\title{
Mathematical Modeling and Experimental Study for Summer Performance of Earth Air Heat Exchanger Integrated with a Solar Greenhouse
}

\author{
Dr. Sujata Nayak, Kapil Narwal, Ruchi Chaudhary \\ (Faculty of Mechanical Engineering, Manav Rachna University, India)
}

\begin{abstract}
A simplified analytical model has been developed to investigate the potential of using the stored thermal energy of ground for space cooling with the help of an earth to air heat exchanger (EAHE) system integrated with the greenhouse located in the premises of Manav Rachna University, Faridabad, Haryana. The analysis was based on quasi-steady state condition. Experiments were conducted extensively during summer period from April to October, but the model, developed, was validated against the clear and sunny days. The performance of the system was evaluated in terms of total cooling potential obtained from EAHE, coefficient of performance (COP) and thermal load leveling. The cooling potential has also been standardized by the characteristic curve of greenhouse similar to that of flat plate collector. Temperatures of greenhouse air were found to be on an average 3-4 OC less than the same green house when operating without EAHE. The temperature fluctuations of greenhouse air were also less when operated with EAHE as compared to without EAHE. Predicted and measured values of greenhouse air temperatures that were verified in terms of root mean square of percent deviation and correlation coefficient, exhibited fair agreement.
\end{abstract}

Keywords: Solar energy, Greenhouse, Earth air heat exchanger, Coefficient of Performance, Thermal load leveling, Thermal modeling

\section{Introduction}

Cooling of a greenhouse is a great problem in the tropical country like India where there is abundance of sunlight and high temperatures in daytime during summer period. Temperature inside the greenhouse rises above desirable level owing to greenhouse effect. Detrimental effects of excessive temperature in the greenhouse cause the loss of stem strength, reduction in flower size, delay of flowering and reduced fruit set in vegetable crops [1-2]. Forced ventilation through exhaust fan and stretching of movable canvas (shade cloth) over the roofs of greenhouse during daytime and removal of it in night time are the conventional methods for reduction of heat flux into the greenhouse [3]. Though the shade cloth reduces the heat flux entering into the greenhouse by the shade rating of cloth (i.e., the percentage of reduction of solar intensity) [4], the heat flux absorbed by the cloth is transmitted to greenhouse enclosure through conduction and convection causing the rise of room air temperature. Fan-pad evaporative cooling system is also an effective means of thermal cooling for a greenhouse but the cooling performance depends on the efficient design of the system. The cooling effect is more pronounced at the entrance of the pad and is gradually diminished towards the mid of the house and at the exit [5]. Fogging system works most efficiently among all evaporative cooling methods if the nozzle efficiency is high and the amount of water is enough. Requirement of high quality water, high-pressure pump, high quality nozzle leading to high initial and operating cost are the disadvantages of the above system [6]. The cooling performance of the intermittently [7] and continuously [8] sprinkling of water during sunshine hours on the external shade cloth stretched over the roof of the greenhouse has also been reported satisfactory for reducing the inside temperature in summer period. But the drawbacks of the methods are the usage of large quantity of good quality water during its scarce availability in summer months, incorporation of efficient spraying system and deterioration of greenhouse cover for its uninterrupted moistness in most of the time. Hence considering the impediments in the cooling performance of the above cooling methods, it is felt necessary to think of a right and effective alternative in reducing the cooling load of greenhouse during summer period. As an alternative means, the vast storage of thermal energy of earth has directed the researchers towards the use of ground as heat source or heat sink for passive heating and cooling applications [9-10] with the help of buried pipe systems.

In buried pipe systems, the nearly constant and stored thermal energy of earth at a certain depth is usually extracted with the help of an arrangement called earth air heat exchanger (EAHE). The stored thermal energy and thereby the earth's surface and sub surface temperatures at any given location, are determined by the balance between the solar energy absorbed at the surface and heat losses by the outgoing long wave radiations and convective heat exchange with ambient air mass [11]. The EAHE use buried pipes for collection and transfer of thermal energy from the ground. 
An earth air heat exchanger system herein is defined [12] as the study of heat transfer between soil, tubes and air flowing through the tube when the tubes are placed below the ground surface at a certain depth where temperature of soil remains nearly constant throughout the year. As air travels the length of the tube, it gets heated in the winter period and gets cooled during the summer period resulting in the space conditioning due to its entry into the enclosed space. Earth air heat exchanger system has the potential of being used throughout the year.

Hence considering the importance of EAHE as a simple, inexpensive and alternative source of energy, the systems has been used in MRU Campus, model greenhouse, India during the summer period with a view to study its thermal performance for cooling of the greenhouse. Its thermal performances has been studied in terms of thermal load leveling, total cooling potential obtained from the arrangement and coefficient of performance (COP) for cooling of greenhouse in composite climate of India.

\section{Basic Principle}

Approximately fixed temperatures of soil at certain depth are much lower in summer and higher in winter than the temperatures of greenhouse air. By allowing the air to flow in the buried pipes of plastic, steel or concrete, there occurs the energy exchange between the flowing air and underground soil depending on the difference of temperatures between them. This exchange of thermal energy induces the variations in the temperatures of moving air and the soil around the pipe. The inlet (suction) and outlet (delivery) ends of the circulating air are positioned at the opposite sides of the enclosure for uniform mixing of air in the space to be conditioned. During the operation, the blower sucks in air from the greenhouse and circulates it through the pipes of earth-coupled heat exchanger. In summer, warm air from the greenhouse sucked through the suction pipe gives up its heat content to the buried pipe by convection, which is then dissipated to the earth by conduction. The cool air from the system is then entered into the greenhouse. In winter, when cold air from inside greenhouse is circulated through the buried pipes, there occurs transfer of heat from earth to the air stream resulting in the increase of delivery air temperature. In the mid period, when indoor temperature is higher than the required level during daytime, the excess heat content of the flowing air is transferred to the earth for reducing undesirable rise of temperature in the enclosure. Thus the enclosed air of greenhouse gets cooled during summer and heated in winter by utilizing the stable thermal content of ground with the help of earth air heat exchanger.

\section{Experimental Set-Up and Observations}

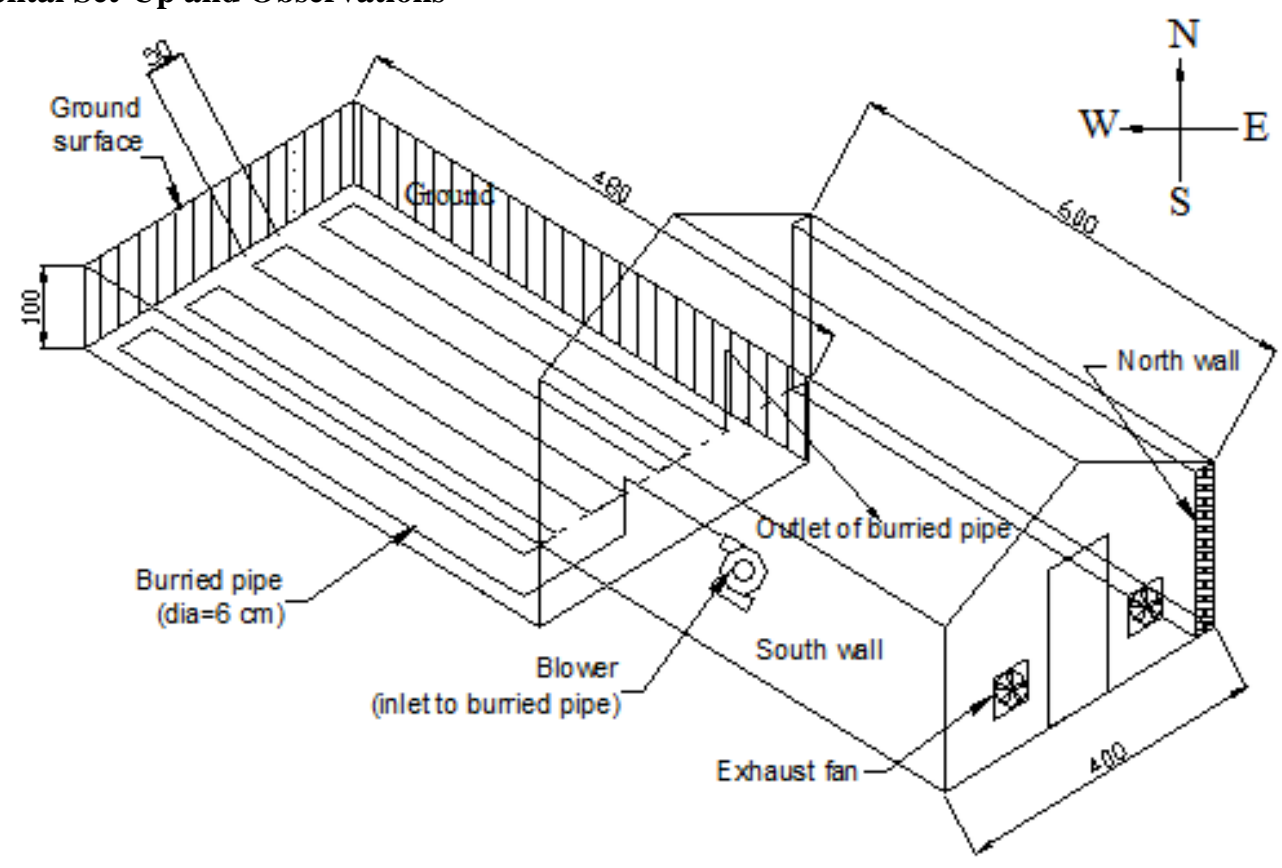

All Dimensions in cm

Fig. 1a Isometric view of even span greenhouse integrated with EAHE arrangement 


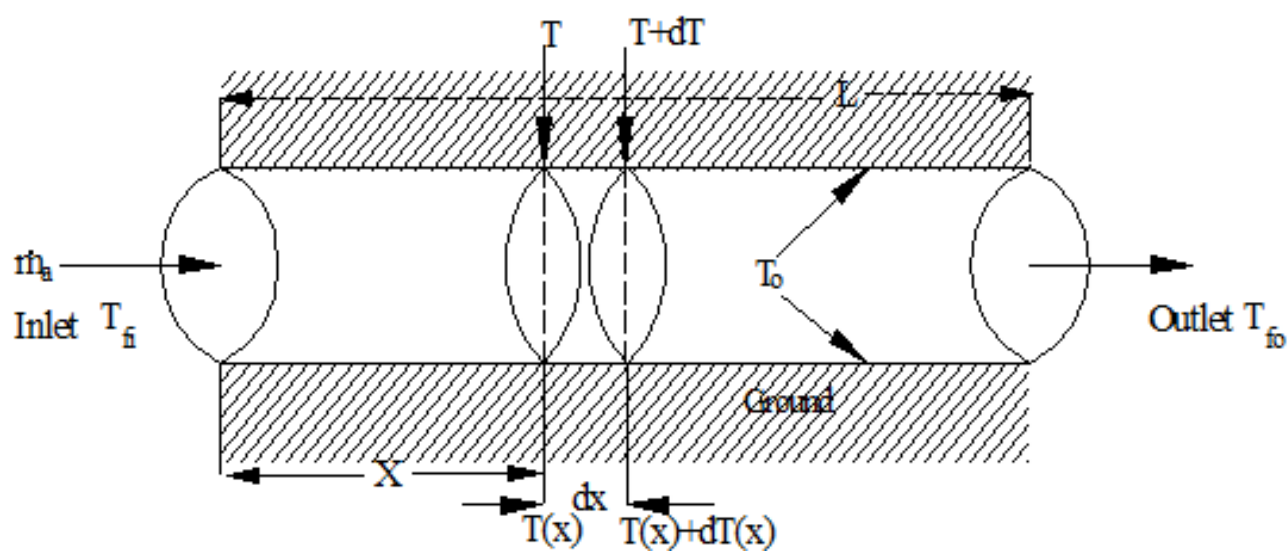

Fig. 1b Energy exchange between ground and flowing air in elementary segment of the buried pipe

The EAHE under study was used in the greenhouse located in the premises of MRU, Faridabad, Haryana. The climate of the place is composite i.e., it remains hot dry for five months, warm and humid for three months, moderate for one month and cold for three months. The absolute maximum temperature of ambient air during summer period is close to $45^{\circ} \mathrm{C}$ while mean maximum is close to $39^{\circ} \mathrm{C}$. The greenhouse combined with EAHE was of even span type of greenhouse with floor area $6 \mathrm{~m} \mathrm{x} 4 \mathrm{~m}$ and was oriented from east to west direction. The EAHE was installed outside in west side of the greenhouse. Total length and diameter of buried pipes used were $39 \mathrm{~m}$ and $0.06 \mathrm{~m}$ respectively. EAHE also consisted of PVC pipes buried under bare surface at the depth of $1 \mathrm{~m}$ in a serpentine manner with 8 nos. of turns. The blower was attached in the suction end of the EAHE. The suction and delivery ends of EAHE were placed in the southwest and northwest corners of the greenhouse for allowing uniform mixing of air. The isometric view of experimental greenhouse integrated with EAHE is shown in Fig. 1a. Experiments were conducted continuously for two days in a week in clear and sunny days from April'2016 to Oct'2016 with $1^{\text {st }}$ day without any heating arrangement and $2^{\text {nd }}$ day with EAHE system. However the experimental validation was done for typical date (clear sunny day) of observations i.e., on 18-05-16 for greenhouse with EAHE, since May is the hottest month for Haryana. Hourly observations of solar radiation and temperatures of air for ambient condition, greenhouse enclosure, suction end and delivery end were recorded during the experimentation with the help of calibrated solarimeter and mercury thermometer, respectively.

\section{Thermal analysis}

The energy balance equations for various components of greenhouse combined with earth to air heat exchanger can be written on the basis of following assumptions:

i. Analysis is based on quasi steady state conditions,

ii. There is no radiative heat exchange between the walls and roofs of greenhouse, due to negligible temperature differences,

iii. Flow of air is uniform along the length of buried pipes,

iv. Heat flow is one-dimensional.

Energy balance equations for north wall, floor and room air of greenhouse are as follows:

a) North wall

$$
\alpha_{n}\left(1-r_{n}\right) F_{n}(1-r)\left\{\sum A_{i} I_{i} \tau_{i}\right\}=h_{n r}\left(\left.T\right|_{y=0}-T_{r}\right) A_{n}+h_{n a}\left(\left.T\right|_{y=0}-T_{a}\right) A_{n}
$$

b) Floor

$$
\alpha_{g}\left(1-r_{g}\right)\left(1-F_{n}\right)(1-r)\left\{\sum A_{i} I_{i} \tau_{i}\right\}=h_{g r}\left(\left.T\right|_{x=0}-T_{r}\right) A_{g}-h_{g \infty}\left(\left.T\right|_{x=0}-T_{\infty}\right) A_{g}
$$

At larger depths, the temperature of ground is assumed to be equal to ambient air temperature, $T_{\infty}=T_{a}$, then Eq. (2) becomes

$$
\alpha_{g}\left(1-r_{g}\right)\left(1-F_{n}\right)(1-r)\left\{\sum A_{i} I_{i} \tau_{i}\right\}=h_{g r}\left(\left.T\right|_{x=0}-T_{r}\right) A_{g}+h_{g \infty}\left(\left.T\right|_{x=0}-T_{a}\right) A_{g}
$$

c) Greenhouse air

$$
\begin{aligned}
& h_{n r}\left(\left.T\right|_{y=0}-T_{r}\right) A_{n}+h_{g r}\left(\left.T\right|_{x=0}-T_{r}\right) A_{g}+\dot{Q}_{u}=\sum A_{i} U_{i}\left(T_{r}-T_{a}\right) \\
& +0.33 N V\left(T_{r}-T_{a}\right)+M_{a} C_{a} \frac{d T_{r}}{d t}
\end{aligned}
$$


The term i.e., $\dot{Q}_{u}$ in Eq. (4) is the useful thermal energy obtained from EAHE and is expressed by the equation,

$\dot{Q}_{u}=F_{R} \dot{m}_{a} C_{a}\left(T_{0}-T_{f i}\right)$

where $F_{R}=1-e^{-\frac{2 \pi r_{1} h_{g f}}{\dot{m}_{a} C_{a}} L^{\prime}}$ (Appendix-1). Now eliminating $\left.T\right|_{y=0}$ from Eq. (1) and after rearrangement,

$h_{n r}\left(\left.T\right|_{y=0}-T_{r}\right)=F_{1} \frac{I_{\text {effN }}}{A_{n}}-U_{n}\left(T_{r}-T_{a}\right)$

where $I_{e f f N}=\alpha_{n}\left(1-r_{n}\right) F_{n}(1-r)\left(\sum A_{i} I_{i} \tau_{i}\right), F_{1}=\frac{h_{n r}}{h_{n r}+h_{n a}}$ and $U_{n}=\frac{\left(h_{n r}\right)\left(h_{n a}\right)}{\left(h_{n r}+h_{n a}\right)}$

Similarly eliminating $\left.T\right|_{x=0}$ from Eq. (3) and after rearrangement,

$h_{g r}\left(\left.T\right|_{x=0}-T_{r}\right)=F_{2} \frac{I_{e f f F}}{A_{g}}-U_{g}\left(T_{r}-T_{a}\right)$

where $I_{\text {effF }}=\alpha_{g}\left(1-r_{g}\right)\left(1-F_{n}\right)(1-r)\left(\sum A_{i} I_{i} \tau_{i}\right) ; F_{2}=\frac{h_{g r}}{h_{g r}+h_{g \infty}} ; U_{g}=\frac{\left(h_{g r}\right)\left(h_{g \infty}\right)}{\left(h_{g r}+h_{g \infty}\right)}$ and $T_{f i}=T_{r}$.

Now substituting Eqs. (6) and (7) in Eq. (4) and simplifying, Eq. (4) can be written in the following first order differential equation,

$\frac{d T_{r}}{d t}+a T_{r}=B(t)$

where $B(t)=\frac{F(t)+(U A)_{e f f} T_{a}}{M_{a} C_{a}}$ and $a=\frac{(U A)_{e f f}}{M_{a} C_{a}} ; F(t)=F_{1} I_{\text {effN }}+F_{2} I_{\text {effF }}+F_{R} \dot{m}_{a} C_{a} T_{o}$

$(U A)_{e f f}=U_{n} A_{n}+U_{g} A_{g}+0.33 N V+\left(\sum A_{i} U_{i}\right)+F_{R} \dot{m}_{a} C_{a}$

$\left(\sum A_{i} I_{i} \tau_{i}\right)=\left(A_{e} I_{e} \tau_{e}+A_{w w} I_{w w} \tau_{w w}+A_{s r} I_{s r} \tau_{s r}+A_{n r} I_{n r} \tau_{n r}+A_{s} I_{s} \tau_{s}\right)$

$\left(\sum A_{i} U_{i}\right)=\left(A_{e} U_{e}+A_{w w} U_{w w}+A_{s r} U_{s r}+A_{n r} U_{n r}+A_{s} U_{s}\right) ; U_{e}=U_{w w}=U_{s r}=U_{n r}=U_{s}=U$

$h_{n a}=\left[\frac{L_{n}}{K_{n}}+\frac{1}{h_{0}}\right]^{-1}, h_{g \infty}=\left[\frac{L_{g}}{K_{g}}\right]^{-1}, U_{n}=\left[\frac{1}{h_{i}}+\frac{L_{n}}{K_{n}}+\frac{1}{h_{0}}\right]^{-1}, U_{g}=\left[\frac{1}{h_{g r}}+\frac{1}{h_{g \infty}}\right]^{-1} ;$

$U=\left[\frac{1}{h_{i}}+\frac{1}{h_{0}}\right]^{-1}, h_{n r}=h_{g r}=h_{g f}=h_{i}$.

The analytical solution of Eq. (8) can be written as

$T_{r}=\frac{\overline{B(t)}}{a}\left(1-e^{-a t}\right)+T_{r o} e^{-a t}$

where, $T_{r o}$ is the greenhouse air temperature at $t=0$ and $\overline{B(t)}$ is the average of $B(t)$ for the time interval

0 and $t$, and $a$ is constant during the time. The average value of $\bar{T}_{r}$ between 0 -t can be obtained as,

$\overline{T_{r}}=\frac{1}{t} \int_{0}^{t} T_{r} d t=\frac{\overline{B(t)}}{a}\left(1-\frac{1-e^{-a t}}{a t}\right)+T_{r 0} \frac{1-e^{-a t}}{a t}$

From Eq. (10), the temperature of air inside greenhouse, combined with earth air heat exchanger can be determined for analysis.

\section{Instantaneous Loss Efficiency $\left(\eta_{L}\right)$ Characteristic Curves For Greenhouse}

The instantaneous loss efficiency $\left(\eta_{L}\right)$ is defined as the ratio of thermal energy lost from greenhouse to the ambient air to input energy and is expressed as 


$$
\eta_{L}=\frac{(U A)_{e f f}\left(T_{r}-T_{a}\right)}{\sum\left(A_{i} I_{i}\right)}
$$

Putting the expressions of $\bar{T}_{r}, B(t), F(t),(U A)_{\text {eff }}$ and $a$ in Eq. (11) and simplifying, the instantaneous loss efficiency becomes,

$$
\begin{gathered}
\eta_{L}=(\alpha \tau)_{e f f}+U_{L} \frac{\left(T_{r 0}-T_{a}\right)}{I} \\
\text { Where }(\alpha \tau)_{e f f}=\frac{F_{1} I_{e f f N}+F_{2} I_{e f f F}+F_{R} \dot{m}_{a} C_{a} T_{0}}{\sum\left(A_{i} I_{i}\right)}\left[1-\frac{1-e^{-a t}}{a t}\right] ; U_{L}=\frac{(U A)_{e f f}}{\sum A_{i}}\left(\frac{1-e^{-a t}}{a t}\right)
\end{gathered}
$$

$I=\sum I_{i}$ and $a t$ is dimensionless. Equation (12) is the function of design and climatic parameters

and is similar to the characteristic equation for flat plate collector (Duffie and Beckman, 1991). This equation is helpful for comparison and standardization of various cooling methods inside the greenhouse.

\section{Computational Procedure And Input Parameters}

The energy balance equations derived for greenhouse with EAHE have been solved with the help of a computer program based on Matlab software. The design and operating parameters given in Table-1 have been used as input parameters for the mathematical model developed. The closeness of predicted and experimental values has been presented with coefficient of correlation $\left(c_{r}\right)$ and root mean square of percent deviation $\left(e_{r}\right)$. Solar radiation falling on different walls and roofs of greenhouse was calculated with the help of Liu and Jordan (1962) [13] formula by using the beam and diffuse components of solar radiation incident on the horizontal surface. The heat removal factor for EAHE has been calculated from steady state energy mechanism as shown in Fig. 1b and as per Eq. (5) as well as in Appendix-1. The mass flow rate of the circulating air was kept constant with $100 \mathrm{~kg} /$ hour. The heating and cooling potential obtained from EAHE was calculated as per the following expressions:

$$
Q_{c}=\sum \dot{m}_{a} C_{a}\left(T_{s c}-T_{d}\right) \Delta t \text { and } C O P=\frac{\text { output energy }}{\text { Energy spent to get output energy }} .
$$

Thermal load leveling gives an idea about the fluctuations of air temperature inside the greenhouse. The less the fluctuations, the better is the environment for plants inside the greenhouse. In summer, TLL should have lower values by incorporating cooling method as compared to TLL without heating arrangement. The temperatures of ground i.e., $T_{o}$ were recorded with the help of data logger through the thermocouples located at the depth of $1.0 \mathrm{~m}$ under EAHE arrangement.

\section{Results And Discussion}

The hourly variations of temperature for ambient air, greenhouse air when operating with EAHE for typical summer day (18-05-2016) and without EAHE (17-05-2016) have been presented in Fig. 2. From the figure, it is seen that the minimum as well as maximum temperatures for ambient air, greenhouse air with EAHE and without EAHE varied between $27-43{ }^{\circ} \mathrm{C}, 21-40{ }^{\circ} \mathrm{C}$ and $27-48{ }^{\circ} \mathrm{C}$ respectively indicating the decrease of minimum as well as maximum air temperature inside the greenhouse with EAHE as compared to ambient air and greenhouse air without EAHE. 


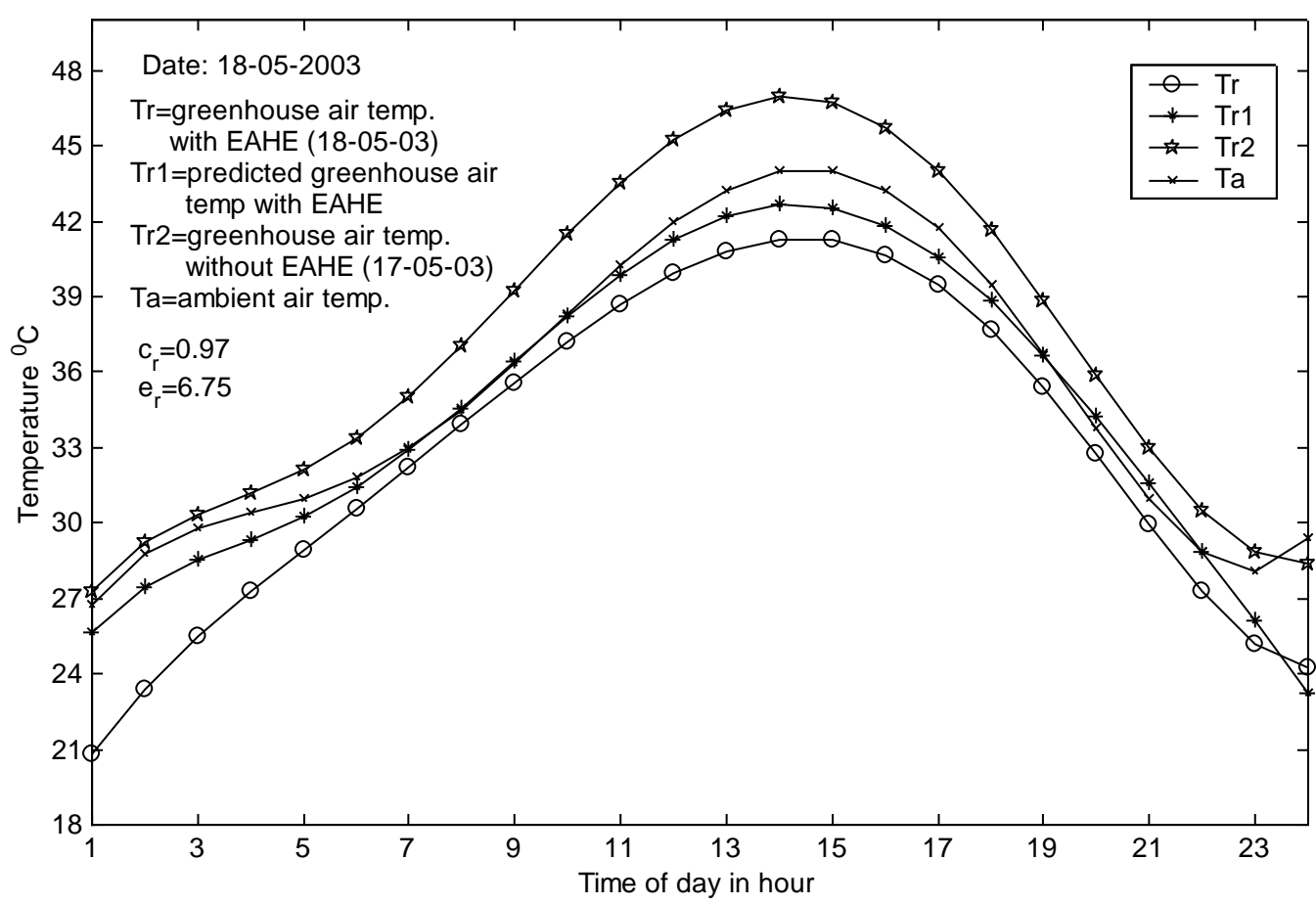

Fig. 2 Hourly variations of greenhouse air temperature for typical summer day by EAHE

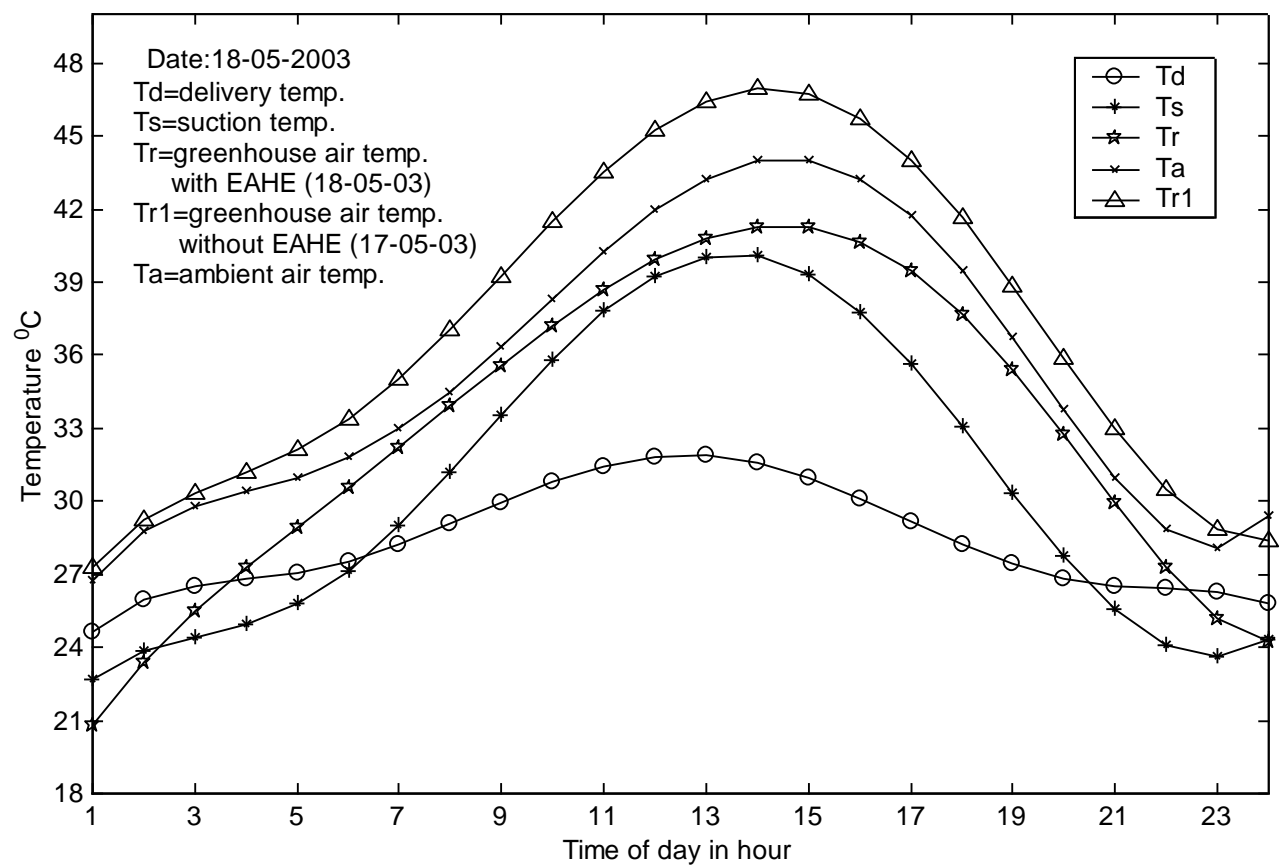

Fig. 3 Hourly variations of suction, delivery, greenhouse air (with and without EAHE) and ambient air temperatures during experimentation

This is due to the entry of cool air to the greenhouse by EAHE arrangement. The temperature of ground on the above day at the depth $(1 \mathrm{~m})$ in which the EAHE system was installed was recorded to be about $27^{\circ} \mathrm{C}$. The predicted values of air temperature in the greenhouse have been validated with their experimental values for the above typical day (18-05-2016) and they showed fair agreement with $\left(c_{r}\right)$ as 0.97 and $\left(e_{r}\right)$ as 6.75 .

By examining closely the daily temperature profiles of greenhouse air from Fig. 3, it is found that the delivery temperatures of EAHE were $5-8^{\circ} \mathrm{C}$ less than the suction temperatures from 9 am to $7 \mathrm{pm}$ (cooling of greenhouse air). Both suction as well as delivery temperatures remained equal at about 7 am and $8 \mathrm{pm}$ (with zero cooling potential obtained from EAHE) and from $9 \mathrm{pm}$ to $6 \mathrm{am}$; the delivery temperatures were $2-3^{\circ} \mathrm{C}$ 
higher than the suction temperatures (heating of greenhouse air). But it was observed that the overall temperatures of greenhouse air were dropped by $5-6{ }^{\circ} \mathrm{C}$ than the same greenhouse when operated without EAHE. Also the temperatures of air were maintained in the range of $21-40^{\circ} \mathrm{C}$ in the greenhouse.

After knowing the suction and delivery temperatures of EAHE as well as mass flow rate, the diurnal variations of total cooling potential obtained from the system for the typical day in the summer months were calculated and have been shown in Fig. 4. From the figure, it is seen that the air in the greenhouse was cooled during peak sunshine hours causing the reduction of its undesirable rise of temperature in the summer period. Similarly the total cooling potentials obtained from EAHE for a typical day in each summer months have been computed and presented in Fig. 5. From the results, it is seen that the cooling potentials obtained from EAHE were higher in the month of May followed by June, July, April, August, September and October. The higher value of cooling potential in May (hottest month) is due to the more differences of temperature in suction and delivery ends. The coefficient of performance determined for typical day in each month has also been discussed in Fig. 6 to know the applicability of the system. The values of coefficient of performance were highest in the month of May (1.75), followed by June (1.53), July (1.3) and April (1.25). However, in the months of August, September and October values of COP were below the dashed line (value less than 1) indicating the discontinuance of the system during these months. The values of thermal load leveling achieved for typical days in each month have also been calculated and presented in Fig. 7 in order to know the efficacy of the system during the study. From the computed results, it is seen that the values of TLL in each month for greenhouse with EAHE were lower than those without EAHE proving the former to be more effective for reducing the daily swings of temperature of air in greenhouse.

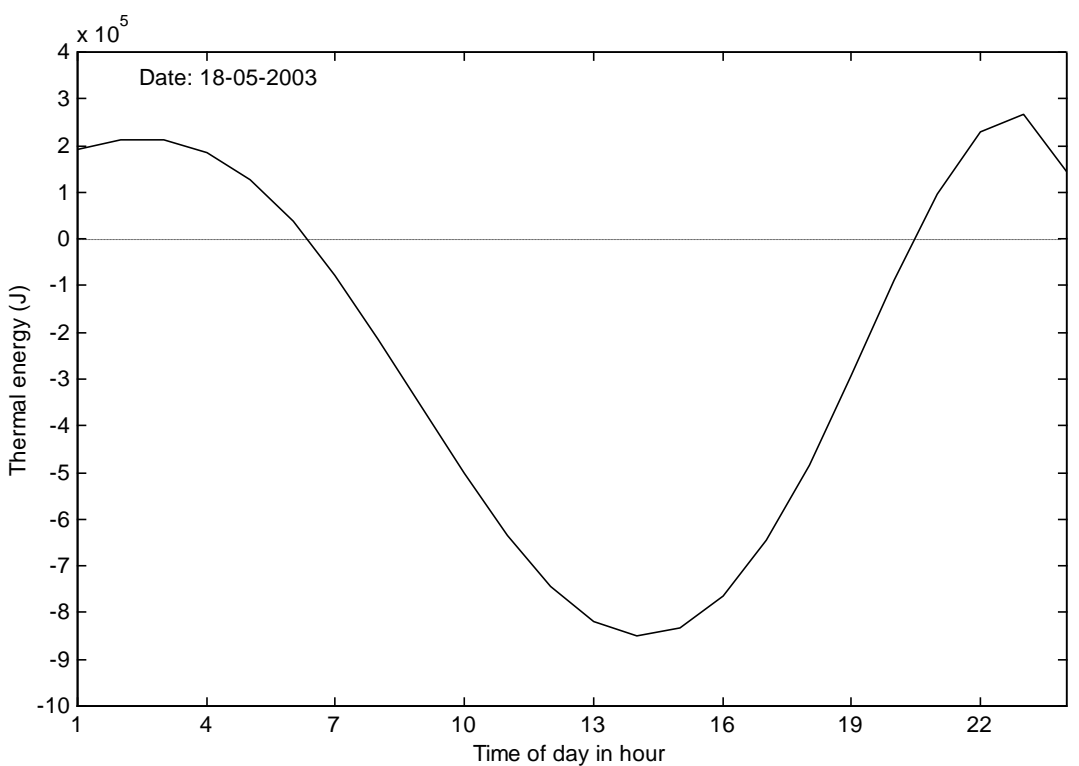

Fig. 4 Hourly variations of cooling potential by EAHE for a typical summer day

图 Total cooling potential

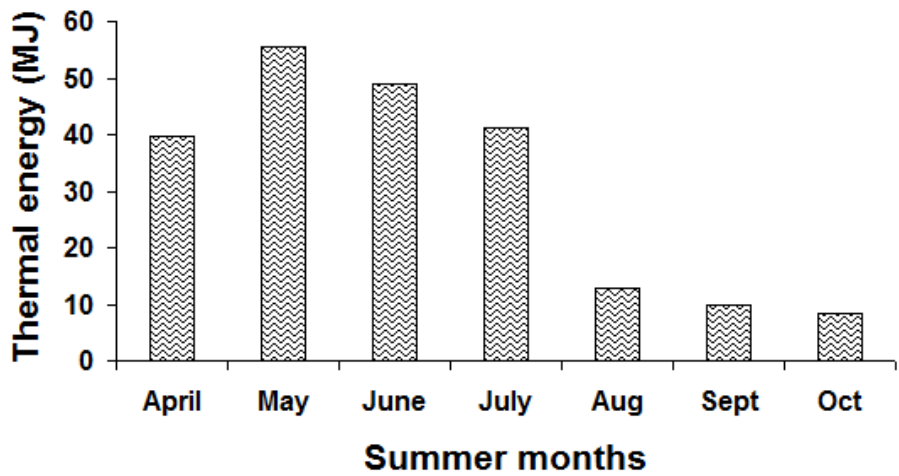

Fig. 5 Monthly variations of total cooling potential obtained from EAHE during experimentations 
After computation of air temperature in the greenhouse, instantaneous loss efficiency characteristic curve was evaluated from Eq. (12) for the greenhouse with and without EAHE. The equation represents the equation of straight line between efficiency in $\mathrm{Y}$-axis and $\left(T_{r o}-T_{a}\right) / I$ in X-axis. The intercept $(\alpha \tau)_{e f f}$ is the gain term where as slope of gradient $\left(U_{L}\right)$ is the loss factor. Instantaneous loss efficiency curves standardize and compare the cooling potential of different cooling methods. The slope of gradient $(\mathrm{m})$ in the curve represents the magnitude of various thermal losses from enclosed air to ambient through greenhouse cover and to the ground via floor where as the intercept (gain term) refers to the thermal energy rise or fall of the enclosure (greenhouse) air particularly by incoming solar radiation and auxiliary heating or cooling arrangements. For cooling of an enclosure, the loss factor should be as maximum as possible and the gain term should be as minimum as practicable. From Fig. 8, it is evident that gain term was less in case of greenhouse with EAHE as compared to without EAHE whereas, the loss factor was more in the former. The reason for the less values of gain term in case of greenhouse with EAHE is due to the mixing of cool air from EAHE arrangement with the enclosed air. Also theoretical and experimental loss efficiency characteristic curves showed good agreement in both the conditions of experiment.

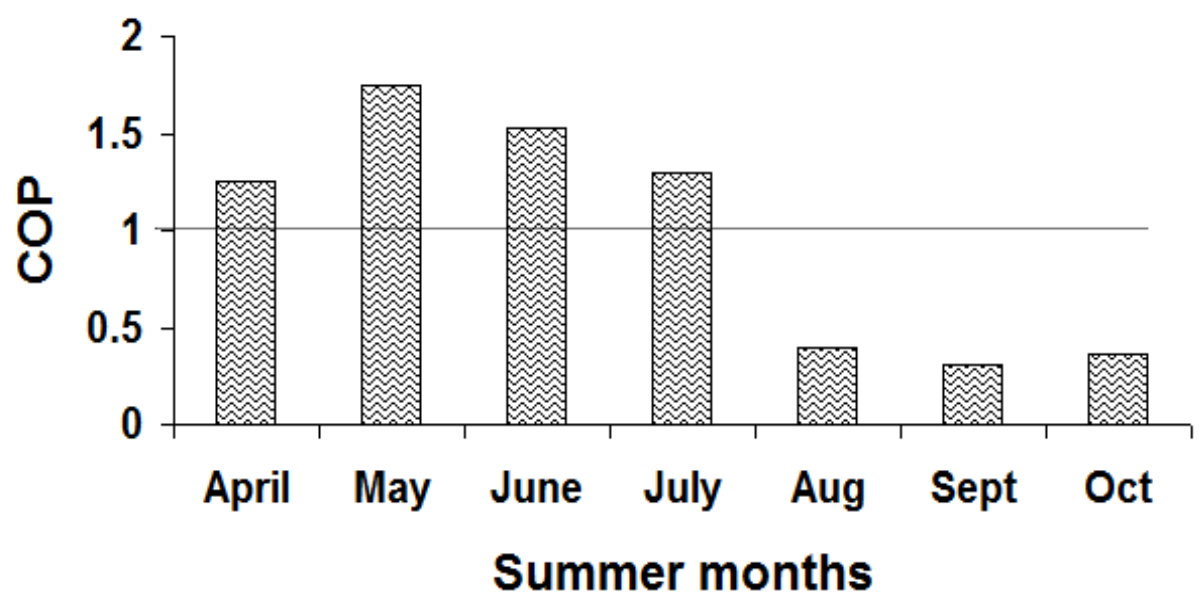

Fig. 6 Monthly variations of coefficient of performance (COP) during experimentations

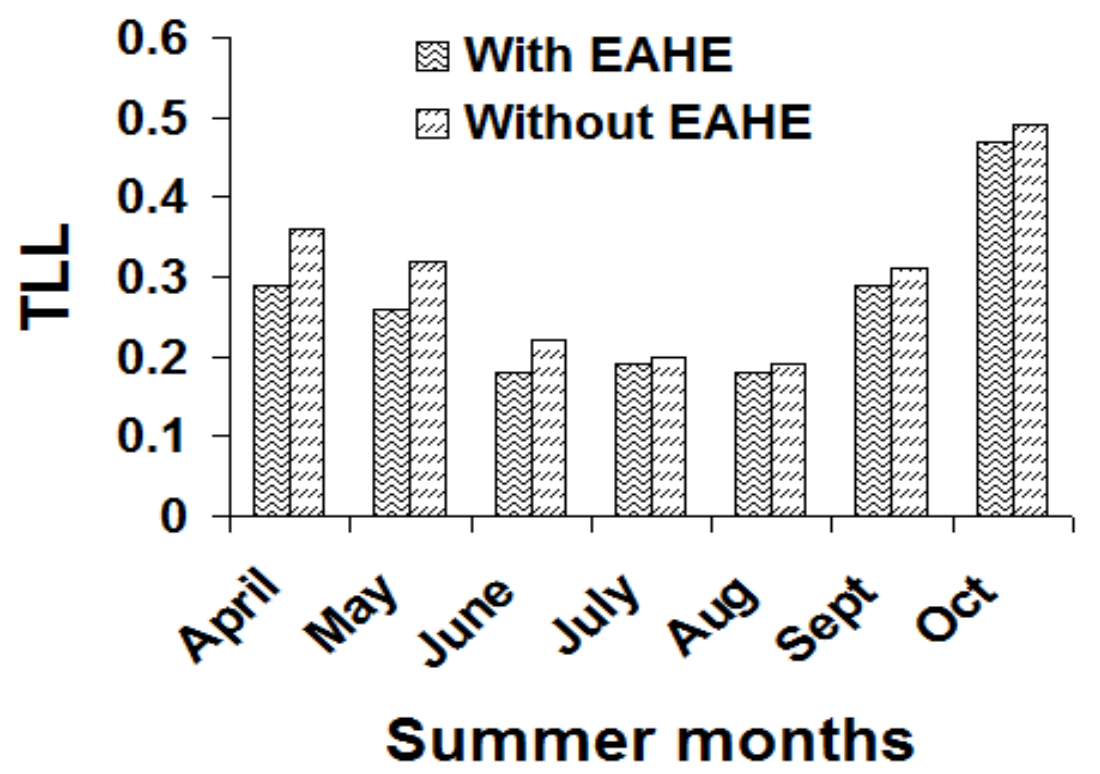

Fig. 7 Monthly variations of thermal load leveling (TLL) during experimentation 


\section{Conclusion}

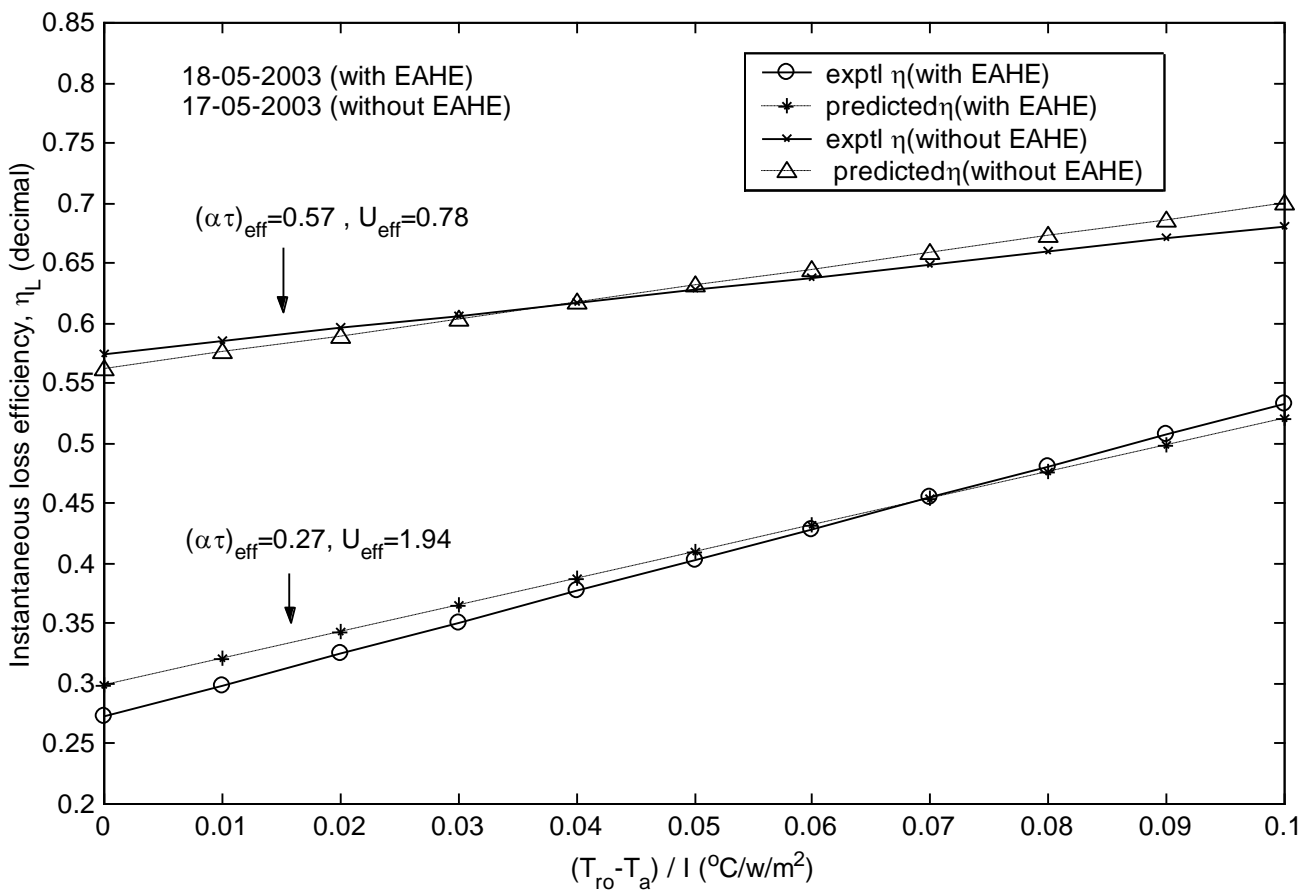

Fig. 8 Instantaneous loss efficiency characteristic curve for greenhouse with and without EAHE

From the above results, the main conclusions for the present study are as follows:

I. There occurs $5-6^{\circ} \mathrm{C}$ reduction of temperatures for greenhouse air during peak sunshine hours in summer period due to the incorporation of EAHE as compared to without EAHE

II. Relative fluctuations of temperature for greenhouse air are less in EAHE arrangement than without that system

III. The predicted and experimental temperatures of greenhouse air in the model developed, with EAHE arrangement exhibit fair agreement.

IV. The computed and experimental loss efficiency characteristic curves for greenhouse compare well with each other.

\section{References}

[1]. Nelson PV. Greenhouse operation and management. Virginia: A prentice Hall Company, 1985

[2]. Cockshull KE, Kofranek AM. High night temperatures delay flowering, produce abnormal flowers and retard stem growth of cut flower chrysanthemums. Scientia Horticulturae 1994; 56:217-234

[3]. Kittas C, Bartzanas T, Jaffrin A. Greenhouse evaporative cooling: measurement and data analysis. Transactions of the ASAE 2001; 44(3): 683-689

[4]. Walker JN, Aldrich RA, Short TH. 1983. Quality of airflow for greenhouse structures. In: ASAE Monograph 1983; (M.A. Hellickson, J.N. Walker, eds ), St. Joseph, Mich: ASAE.

[5]. Willits DH. Constraints and limitations in greenhouse cooling: challenges for the next decade. Acta Horticulturae 2000; 534:57-66

[6]. Fang W. Greenhouse cooling in subtropical regions. Acta Horticulturae 1995;399:37-48

[7]. Willits DH, Peet MM. Intermittent application of water to an externally mounted greenhouse shade cloth to modify cooling performance. Transactions of the ASAE 2000; 43(5): 1247-1252

[8]. Ghosal MK, Tiwari GN, Srivastava NSL. Modeling and experimental validation of a greenhouse with evaporative cooling by moving water film over external shade cloth. Energy and Buildings 2003; 35:843-850

[9]. Tombazis A, Argiriou A, Santamouris M. Performance evaluation of passive and hybrid cooling components for a hotel complex. Solar Energy 1990; 9:1-12

[10]. Santamouris M, Argiriou A, Vallindras M. Design and operation of a low energy consumption passive solar agricultural greenhouse. Solar Energy, 1994; 52 (5):371- 378

[11]. Sodha MS, Bansal NK, Seth AK. Variation of ground temperature distribution. Applied Energy 1981; 8: 245

[12]. Puri VM. Earth tube heat exchanger performance correlation using boundary element method. Transactions of the ASAE 1987; 30(2): 514-520

[13]. Liu BYH, Jordan RC. Daily insolation on surfaces tilted towards the equator. ASHRAE Journal 1962; 3(10): 53

[14]. Singh RD, Tiwari GN. Thermal heating of controlled environment greenhouse: a transient analysis. Energy Conversion and Management 2000; 41: 505-522

[15]. Duffie JA, Beckman WA. Solar Engineering of Thermal Processes, $2^{\text {nd }}$ edition. New York: John Wiley and Sons. 1991 


\section{Nomenclature}

A $\quad-\quad$ Area, $\mathrm{m}^{2}$

$C_{a} \quad-\quad$ Specific heat of air, $\mathrm{J} / \mathrm{kg}{ }^{0} \mathrm{C}$

$F_{n} \quad-\quad$ Fraction of solar radiation falling on north wall, dimensionless, decimal

$F_{R} \quad$ - $\quad$ Heat removal factor for EAHE from underground earth's surface

$h_{i} \quad-\quad$ Heat transfer coefficient from greenhouse cover to inside Green house air, W/m $/ \mathrm{m}^{2} 0 \mathrm{C}$, $(2.8+3.0 v),[15]$

$h_{o} \quad$ - Heat transfer coefficient from greenhouse cover to ambient, W/m $0 \mathrm{C}$, $(5.7+3.8 v),[15]$

$h_{g f} \quad$ - Convective heat transfer coefficient from underground earth's surface to flowing air inside the buried pipes, $\mathrm{W} / \mathrm{m}^{2}{ }^{0} \mathrm{C}$

$h_{g \infty} \quad$ - $\quad$ Heat transfer coefficient from floor to larger depth of ground, $\mathrm{W} / \mathrm{m}^{2}{ }^{0} \mathrm{C}$

$h_{n a} \quad$ - Heat transfer coefficient from north brick wall to ambient, $\mathrm{W} / \mathrm{m}^{2}{ }^{0} \mathrm{C}$

$h_{n r} \quad-\quad$ Heat transfer coefficient from north wall to greenhouse air, $\mathrm{W} / \mathrm{m}^{2}{ }^{0} \mathrm{C}$

$h_{g r} \quad$ - $\quad$ Heat transfer coefficient from floor to greenhouse air, $\mathrm{W} / \mathrm{m}^{2}{ }^{0} \mathrm{C}$

I $\quad$ - $\quad$ Solar radiation falling on inclined surface or greenhouse cover, $\mathrm{W} / \mathrm{m}^{2}$

$K \quad$ - Thermal conductivity, $\mathrm{W} / \mathrm{m}{ }^{0} \mathrm{C}$

$K_{g} \quad-\quad$ Thermal conductivity of ground, $\mathrm{W} / \mathrm{m}^{0} \mathrm{C}$

$L \quad$ - Thickness, $m$

$L^{\prime} \quad$ - $\quad$ Total length of buried pipes (EAHE), $m$

$\dot{m}_{a} \quad$ - $\quad$ Mass flow rate of air entering into the buried pipes, $\mathrm{kg} / \mathrm{s}$

$M_{a} \quad$ - $\quad$ Total mass of air in greenhouse enclosure, $\mathrm{kg}$

$N \quad$ - Number of air changes per hour

$Q_{c} \quad-\quad$ Cooling potential offered by EAHE for greenhouse air, J

$\dot{Q}_{u} \quad$ - $\quad$ Useful thermal energy obtained from EAHE for greenhouse air, W

$r \quad$ - $\quad$ Reflectivity from greenhouse cover, dimensionless, decimal

$r_{g} \quad-\quad$ Reflectivity from greenhouse floor, dimensionless, decimal

$r_{n} \quad-\quad$ Reflectivity from north wall, dimensionless, decimal

$r_{1} \quad$ - $\quad$ Radius of buried pipe in EAHE, $\mathrm{m}$

$t \quad$ - $\quad$ Time in second

$\Delta t \quad$ - $\quad$ Time interval in hour

$T \quad$ - Temperature, ${ }^{0} \mathrm{C}$

$T_{d} \quad$ - $\quad$ Delivery temperature, ${ }^{0} \mathrm{C}$

$T_{o} \quad$ - $\quad$ Temperature of ground in which pipes are spread in EAHE, ${ }^{0} \mathrm{C}$

$T_{f i} \quad-\quad$ Temperature of inlet fluid or temperature at suction point, ${ }^{0} \mathrm{C}$ for EAHE

$T_{s c} \quad-\quad$ Suction temperature, ${ }^{0} \mathrm{C}$

$U \quad$ - $\quad$ Overall heat transfer coefficient for greenhouse cover, $\mathrm{W} / \mathrm{m}^{20} \mathrm{C}$

$U_{g} \quad-\quad$ Overall heat transfer coefficient from greenhouse air to floor, $\mathrm{W} / \mathrm{m}^{2}{ }^{0} \mathrm{C}$

$(U A) \quad-\quad$ Overall heat loss from greenhouse, $\mathrm{W} /{ }^{0} \mathrm{C}$

$v \quad-\quad$ Velocity of air, $\mathrm{m} / \mathrm{s}$

$V \quad$ - $\quad$ Volume of greenhouse, $\mathrm{m}^{3}$

\section{Greek letters}

$\alpha \quad$ - $\quad$ Absorptivity, dimensionless 
$\tau \quad$ - $\quad$ Transmissivity, dimensionless

$\infty \quad$ - $\quad$ Infinity (at larger depth)

$(\alpha \tau)_{e f f}$ - Effective transmittance-absorptance product for greenhouse

\section{Subscript}

$\begin{array}{lll}a & - & \text { Ambient } \\ e & - & \text { East wall of greenhouse } \\ g & - & \text { Floor of greenhouse } \\ i & - & \text { Different walls and roofs of greenhouse } \\ n & - & \text { North wall } \\ r & - & \text { Greenhouse room } \\ s & - & \text { South wall } \\ n r & - & \text { North roof } \\ s r & - & \text { South roof } \\ w w & - & \text { West wall } \\ \text { eff } & - & \text { Effective }\end{array}$

\section{List of figure captions}

Fig. 1a

Isometric view of even span greenhouse integrated with EAHE arrangement

Fig. 1b

Energy exchange between ground and flowing air in elementary segment of buried pipe

Fig. 2 Hourly variations of greenhouse air temperature for typical summer day by EAHE

Fig. 3 Hourly variations of suction, delivery, greenhouse air (with and without EAHE) and ambient air temperatures during experimentation

Fig. 4 Hourly variations of cooling potential by EAHE for a typical summer day

Fig. 5 Monthly variations of total cooling potential obtained from EAHE during experimentations

Fig. 6 Monthly variations of coefficient of performance (COP) during experimentations

Fig. 7 Monthly variations of thermal load leveling (TLL) during experimentations

Fig. 8 Instantaneous loss efficiency characteristic curve for greenhouse with and without EAHE

\begin{tabular}{|l|l|l|l|l|l|}
\hline Parameters & Values & Parameters & Values & Parameters & Values \\
\hline$A_{e}$ & $8.3 \mathrm{~m}^{2}$ & $h_{i}$ & $2.8 \mathrm{~W} / \mathrm{m}^{2}{ }^{0} \mathrm{C}$ & $N$ & $1-300$ \\
\hline$A_{f}$ & $24.0 \mathrm{~m}^{2}$ & $h_{o}$ & $5.7 \mathrm{~W} / \mathrm{m}^{2}{ }^{0} \mathrm{C}$ & $r_{1}$ & $0.03 \mathrm{~m}$ \\
\hline$A_{n}$ & $12.0 \mathrm{~m}^{2}$ & $h_{n a}$ & $1.9 \mathrm{~W} / \mathrm{m}^{2}{ }^{0} \mathrm{C}$ & $U$ & $1.8 \mathrm{~W} / \mathrm{m}^{2}{ }^{0} \mathrm{C}$ \\
\hline$A_{s}$ & $12.0 \mathrm{~m}^{2}$ & $h_{g r}$ & $5.7 \mathrm{~W} / \mathrm{m}^{2} \mathrm{C}$ & $V$ & $0.5-1.5 \mathrm{~m} / \mathrm{s}$ \\
\hline$A_{n r}$ & $13.8 \mathrm{~m}^{2}$ & $h_{n r}$ & $5.7 \mathrm{~W} / \mathrm{m}^{2}{ }^{0} \mathrm{C}$ & $V$ & $60 \mathrm{~m}^{3}$ \\
\hline$A_{s r}$ & $13.8 \mathrm{~m}^{2}$ & $K_{n}$ & $0.84 \mathrm{~W} / \mathrm{m}^{0} \mathrm{C}$ & $r_{g}$ & 0.2 \\
\hline$A_{w w}$ & $10.0 \mathrm{~m}^{2}$ & $K_{g}$ & $0.52 \mathrm{~W} / \mathrm{m}^{0} \mathrm{C}$ & $r_{n}$ & 0.2 \\
\hline$C_{a}$ & $1012 \mathrm{~J} / \mathrm{kg}{ }^{0} \mathrm{C}$ & $L^{\prime}$ & $39 \mathrm{~m}$ & $\alpha_{g}$ & 0.4 \\
\hline$F_{n}$ & $0.09-0.15$ & $L_{g}$ & $1 \mathrm{~m}$ & $\alpha_{n}$ & 0.6 \\
\hline$F_{R}$ & 0.64 & $\dot{m}_{a}$ & $0.02 \mathrm{~kg} / \mathrm{s}$ & $\tau$ & 0.5 \\
\hline$h_{g f}$ & $2.8 \mathrm{~W} / \mathrm{m}^{2}{ }^{0} \mathrm{C}$ & $M_{a}$ & $72 \mathrm{~kg}$ & & \\
\hline
\end{tabular}

Table. 1 Input parameters used for computations

\section{APPENDIX-I}

Calculation of heat removal factor $\left(F_{R}\right)$ in earth air heat exchanger

The assumptions made for derivation of heat removal factor are same as written in section (4) Let the infinitesimal element of buried pipe be $d x$ in the direction of fluid (air) flow as shown in fig. 1b. The energy balance in the elemental section becomes 


$$
\dot{m}_{a} C_{a} \frac{d T(x)}{d x} d x=\left(2 \pi r_{1}\right) h_{g f}\left\{T_{0}-T(x)\right\} d x
$$

where $\dot{m}_{a}=\pi r^{2} \rho_{a} v \quad$ and $h_{g f}=2.8+3.0 v$ and rearranging Eq. (1.1), new equation becomes

$$
\frac{d T(x)}{T_{0}-T(x)}=\frac{2 \pi r_{1} h_{g f}}{\dot{m}_{a} C_{a}} d x
$$

On solving Eq. (1.2),

$$
-\log \left\{T_{o}-T(x)\right\}=\frac{2 \pi r_{1} h_{g f}}{\dot{m}_{a} C_{a}} x+c
$$

where $c$ is the constant of integration.

$$
\text { At } x=0 ; \quad T(x)=T_{f i} \Rightarrow c=-\log \left(T_{o}-T_{f i}\right)
$$

Substituting Eq. (1.4) in Eq. (1.3) and by rearranging, new equation becomes

$$
\frac{T(x)-T_{o}}{T_{f i}-T_{o}}=e^{-\frac{2 \pi r_{1} h_{g f}}{\dot{m}_{a} C_{a}} x}
$$

After simplification of Eq. (1.5), one can get

$$
T(x)=T_{o}\left(1-e^{-\frac{2 \pi r_{1} h_{g f}}{\dot{m}_{a} C_{a}} x}\right)+T_{f i} e^{-\frac{2 \pi r_{1} h_{g f}}{\dot{m}_{a} C_{a}} x}
$$

Applying boundary condition i.e., at $x=L^{\prime},\left.\quad T(x)\right|_{x=L^{\prime}}=T_{f_{o}}$

Substituting Eq. (1.7) in Eq. (1.6), Eq. (1.6) becomes

$$
T_{f o}=T_{o}\left(1-e^{-\frac{2 \pi r_{1} h_{g f}}{\dot{m}_{a} C_{a}} L^{\prime}}\right)+T_{f i} e^{-\frac{2 \pi r_{1} h_{g f}}{\dot{m}_{a} C_{a}} L^{\prime}}
$$

Now subtracting $T_{f i}$ from Eq. (1.8) and after simplification,

$$
\begin{aligned}
& T_{f o}-T_{f i}=\left(T_{o}-T_{f i}\right)\left(1-e^{-\frac{2 \pi \eta_{1} h_{g f}}{\dot{m}_{a} C_{a}} L^{\prime}}\right) \\
& \dot{Q}_{u}=\dot{m}_{a} C_{a}\left(T_{f o}-T_{f i}\right)
\end{aligned}
$$

Putting Eq. (1.9) in Eq. (1.10), the final equation becomes

$\dot{Q}_{u}=\dot{m}_{a} C_{a}\left(T_{o}-T_{f i}\right)\left(1-e^{-\frac{2 \pi r_{1} h_{g f}}{\dot{m}_{a} C_{a}} L^{\prime}}\right)$

when $L^{\prime} \rightarrow \infty, \dot{Q}_{u}=\dot{m}_{a} C_{a}\left(T_{o}-T_{f i}\right)$

and $L^{\prime} \rightarrow 0, \dot{Q}_{u}=0$

$\dot{Q}_{u}=F_{R} \dot{m}_{a} C_{a}\left(T_{o}-T_{f i}\right)$

where $F_{R}=\left(1-e^{-\frac{2 \pi r_{1} h_{g f}}{\dot{m}_{a} C_{a}} L^{\prime}}\right)$ 